\title{
Collaboration, Co-Optation or Navigation? The Role of Civil Society in Disaster Governance in India
}

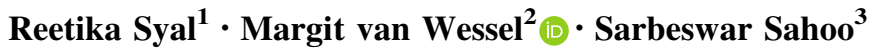

Accepted: 6 March 2021/Published online: 26 March 2021

(C) The Author(s) 2021

\begin{abstract}
Existing research on civil society organizations (CSOs) facing restricted civic space largely focuses on the crackdown on freedoms and CSOs' strategies to handle these restrictions, often emphasizing impact on their more confrontational public roles. However, many CSOs shape their roles through collaborative relations with government. Drawing on interviews with state agencies and CSOs, this article analyes state-CSO collaboration in the restricted civic space context of disaster risk reduction in India. Findings are that the shaping of CSOs' roles through collaboration under conditions of restricted civic space is only partly defined by the across-the-board restrictive policies that have been the focus of much existing research on restricted civic space and its implications for CSOs. Interplay at the level of individual state agencies and CSOs, based on mutual perceptions, diverse organizationlevel considerations and actions, and evolving relations, shape who collaborates with whom and to what effect. This article thus stresses interplay and agency, moving away from simple understandings of co-optation, and calling for a more differentiated approach to the study of state-civil society collaboration under conditions of restricted civic space, with close attention to navigation.
\end{abstract}

Keywords Civic space $\cdot$ Collaboration $\cdot$ Co-optation . Disaster risk reduction $\cdot$ India

Margit van Wessel

Margit.vanwessel@wur.nl

1 Jain Deemed-To-Be University, Bangalore, India

2 Wageningen University \& Research, Hollandseweg 1, $6706 \mathrm{KN}$ Wageningen, The Netherlands

3 Indian Institute of Technology Delhi, New Delhi, India

\section{Introduction}

In recent years, many states have restricted the space for civil society to carry out their roles-especially political ones (CIVICUS, 2020; Dupuy et al., 2016; Hossain et al., 2018; Rutzen, 2015; Toepler et al., 2020). These restrictions are not a range of isolated incidents, but inherently structural in nature, where states have deliberately and systematically attempted to undermine civic space (Buyse, 2018). This has given rise to an important body of research that focuses on the strategies by which states restrict civil society. For example, Van der Borgh and Terwindt (2012, pp. 1070-1072), integrating existing research, distinguished five sets of actions and policies that can restrict operational space for CSOs: physical harassment and intimidation; preventative and punitive measures; administrative restrictions; stigmatization and negative labelling; and pressure in institutionalized forms of interaction and dialogue between government entities and civil society, distinguishing co-optation or closure of newly created spaces.

While some of these studies discuss the strategies and justifications used by states to restrict civil society, others have focused on the effects of restrictions, charting how these delimit and reshape the nature of civil society and its operations. Common effects are the stopping of operations, shifting from advocacy to service delivery (Broeckhoven et al., 2020), shifting topic (Van der Borgh \& Terwindt, 2014) and depoliticization of the advocacy (Tadesse \& Steen, 2019). A final, smaller topic of attention is the way CSOs may seek to respond strategically to navigate restrictions to protect their operational space. Researchers point to such strategies as reframing into less-threatening language, shifting from national-level to local-level advocacy or from agenda-setting advocacy to implementation 
(Fransen et al., 2020), the management of visibility (Van Wessel et al., 2019) and the building of trustful relations with state actors (Tadesse \& Steen, 2019).

Much of this research focuses on restrictions as damaging the claim-making role of civil society (Toepler et al., 2020), which is often executed in the public sphere and sometimes in consultation with government agencies. Work on the crackdown on civic space raises doubts about whether this role, essential for civil society's contribution to articulating and promoting alternatives (Bebbington et al., 2008), and including less-heard views and interests can be executed in many contexts today, especially considering how restrictions obstruct autonomy and silence challenging voices. The constraints on civic space are often selective, with new restrictions mostly affecting human rights defenders, social movements, and marginalized and disempowered groups (Hossain et al., 2018, pp. 7-8, 14; Skokova et al., 2018). Previous work on this topic has largely focused on restriction of freedoms (e.g. of expression, association, and assembly) and their expression through, for instance, confrontational advocacy strategies in the public sphere, where regimes are openly challenged (Lewis, 2013).

Notably, much of this research, taking autonomy and voice as central to the discussion, does not go much into what happens in collaborative relations between states and CSOs, even as collaborations are common. The attention that is there mostly concerns the nature and implications of co-optation: situations in which CSOs are allowed to participate within fixed limits in processes of policy formulation, decision-making and implementation, while denying participants significant influence on fundamental decisions (Wischerman et al. 2018, p. 98). There is also attention for legitimation roles, in which CSOs through their contribution to meeting societal needs and legitimating state ideology legitimize and thereby strengthen the state (Skokova et al., 2018; Toefler et al., 2020).

While some of this literature seeks to develop broadly applicable typologies of e.g. motivations, roles and implications (Toepler et al., 2020), some of it (also) emphasizes the need to look closely to the interplay that can be found in specific cases and contexts, zooming in on the role of agency and manoeuvring of individual state agencies and CSOs (Spires, 2011; Heiss, 2017; Wischerman et al. 2018).

It is here that we seek to contribute, exploring the idea that for CSOs that collaborate with the state, their roles will at least partly take shape through the interplay between state and CSOs and the possibilities offered by the relations. Our starting point is that in day-to-day governance, individual government agencies and CSOs entering into collaboration engage with each other at a level where interests and agendas converge. Personal perspectives and interdependencies, and diverse forms of relating may also come into play. In this article, we investigate how state actors and CSOs relate to each other as collaborators within a context of restricted civic space. Using disaster governance as a case, we ask: How does state-civil society interplay shape CSO collaboration in disaster governance in India? We answer this question through the following sub-questions: what roles do state agencies assign to CSOs? What criteria do state agencies use to select CSOs to work with? What roles do CSOs take up in the collaboration, and how do they navigate the possibilities of these roles considering their own agendas?

\section{State-Civil Society Relations}

It is widely acknowledged that the role of civil society in constituted in its relation with the state. Since Hegel, states have enjoyed supremacy in the public sphere and are placed above civil society. Much civil society literature stresses its autonomous role as a countervailing power. However, as Chandhoke (2001, p.8) notes, 'the very state that civil society supposedly positions itself against, enables the latter in the sense that it provides the legal and the political settings for the sphere to exist and maintain itself'. In other words, the state acts as a precondition for the existence of civil society. Considering the importance of states, Krygier, (1996) argues that 'strong' and 'facilitating' states are a prerequisite for the growth and functioning of civil society. For him, states may be strong in various ways. For example, despotic and authoritarian states obstruct civil society by preventing it to emerge or suppressing it when it has already emerged, as civil society challenges the legitimacy of these states. This was evident in 1970s and 80s in former communist states of Eastern Europe and Latin America (O’Donnell \& Schmitter, 1986; Sahoo, 2013), and continues in countries like China and Russia and lately Hungary, Poland and Turkey. By contrast, liberal democracies are examples of strong, facilitating states, which provide favourable conditions for the emergence and growth of civil society. For Krygier (1996), while strong obstructive states like authoritarianism are detrimental to civil society, weak states are no better; they lack the basic rule of law that is required to protect the autonomy of civil society. Other literature stresses interdependencies between state and civil society, with the state requiring civil society's recognition as legitimate power-holder, and its collaboration in meeting societal needs (Heiss, 2017). More generally speaking, civil society is widely considered a necessary element for inclusive and democratic development, with main and often interconnected roles including service delivery, capacity strengthening, knowledge production, advocacy and collaborative roles in governance, and mobilization and organization of societal groups around issues and interests. While not often embracing all of these roles, states commonly allow for CSOs to play some important development roles, especially when state 
capacities to provide key services are insufficient (Lewis et al. 2021).

At the same time, the diversity of civil society and the manoeuvring of that diversity by the state are important dimensions of the interplay between state and civil society. In general terms, literature already points to considerations that may come in for states. States often find an active, engaged and empowered civil society threatening (Weinstein \& Christensen, 2013). States may perceive a threat coming from 'uncivil' elements within civil society that may hinder democratic development or the state as such (Amarasingam et al., 2020; Chambers \& Kopstein, 2001; Krygier, 1996; Sahoo, 2013). States may also avoid collaborating with and suppress CSOs that question their specific development model (see e.g. Talukdar, 2018). Christensen and Weinstein (2013) add that regime vulnerability is a strong predictor of restrictions on civil society. Furthermore, longer-term developments in the way civil society manifests itself can shape ways of relating in new directions. For example, developments include democracy promotion (i.e. CSOs questioning state policies); development cooperation (i.e. CSO autonomy owing to foreign funding); and information and media technology (i.e. anti-state mobilization through social media) may lead states to constrict civic space. Terrorism, counter-terrorism and securitization (i.e. security justifications) may also lead to such constricting (Buyse, 2018, p.974). States are thus selective in their approach in collaborating with CSOs, acting on their understanding of state and civil society roles as well as analysis of civil society and its behaviour in relation to the state.

\section{State-Civil Society Collaborations}

Existing literature on state-CSO collaborations in conditions of restricted civic space mostly focuses on the implications of collaboration with authoritarian and hybrid states (combining democratic institutions and repression) for CSOs' roles. Co-optation is a commonly discussed risk, which has been discussed mainly in terms of CSOs providing services in line with the state's goals (Lewis, 2013; Spires, 2011). Thus, CSOs do not necessarily contribute to democratization (Lewis, 2013) and may actually work against it. Collaboration is mainly considered as one more way in which CSOs' role voicing societal views and demands gets diminished, while at the same time establishing some ways to serve society through collaboration. CSOs may be motivated in this by a wish to balance between mission-driven and instrumental needs (Heiss, 2017, p. 269; Giersdorf \& Croissant, 2011). Lorch and Bunk (2017) provided an overview of how states may use CSOs to legitimate authoritarian rule: CSOs offer a facade of democracy, where organization is permitted but space for critique is limited, embedding civil society in bureaucratic practices. By complying with and adapting to constraints so that they can act effectively, CSOs reaffirm the authoritarian order and potentially contribute to its legitimacy, Lorch and Bunk argue. CSOs may also strengthen the regime discourse, while critical CSO voices are suppressed (Lorch \& Bunk, 2017, pp. 990-991). At the same time, when CSOs use available avenues for limited participation, social discontent is depoliticized and channelled into forms of collective action that provide learning about pressing demands and facilitate responsiveness without threatening the authoritarian or hybrid state. Through service delivery, CSOs may also contribute to meeting fundamental social needs not met by the state apparatus.

While this literature suggests careful assessment and management of CSO roles by the state, a few publications show similarly careful assessment and management from CSOs' side. Spires (2011) shows how 'illegal' CSOs in China engage local officials to be able to do the service delivery work they want to do "constructing a relationship that is symbiotic in that CSOs are looking to meet social needs, while government officials, especially at the local level, seek to make sure all 'problems' in their jurisdictions are dealt with in ways that do not attract unfavourable attention from their higher-ups' (p. 12). Tadesse and Steen, (2019) similarly show how CSOs in Ethiopia navigate civic space by working on their individual position with state actors, for example by seeking to enhance their autonomy through building strong relations with state actors who can help ease state control. Kulmala, (2016), writing about CSOs in Russia, shows how ostensibly apolitical, serviceoriented organizations, within these roles, can still be seen taking up political roles, for example by creating new services for ignored groups like HIV-positive mothers, or articulating and thereby politicizing issues like domestic violence. Importantly, these roles develop in interconnection with service work.

These publications indicate that relations between states and CSOs, and thus CSO roles, develop in interplay (cf. Pauly et al., 2016), and collaborations can offer possibilities, also in authoritarian and hybrid states. In present conditions of increasingly constricted civic space, these questions are important in light of challenges of inclusive development. Recent literature does approach the role of associations in authoritarian and hybrid contexts as complex, taking these as 'polyvalent', and stressing the importance of taking a 'theoretically grounded, power-focused, and relational perspective', and of studying the complex relations and interactions between state and society (Wischerman et al., 2018). However, questions of interplay have thus far hardly been addressed in ways that consider the sensemaking of state and CSOs at the level of 
individual relations between CSOs and state agencies in contexts of collaboration-while relations and thus possibilities may typically develop exactly in such situations.

\section{Case and Methods}

For this study, we selected India as a case that has a thriving and diverse civil society (Van Wessel et al., 2018, 2019, 2020; Katyaini et al., 2021). While state-civil society relations in India have undergone several transformations under different political regimes-ranging from confrontation and cooperation to co-optation-most recently civic space is facing heavy restrictions (Chakrabarti et al., 2018), as we will discuss below. Despite such restrictions, collaboration between state and civil society is common. We selected the domain of disaster governance as one in which the state's and CSOs' agendas converge on many fronts but where there are also substantial differences. Many CSOs advance agendas differing from the state's regarding, for example, the importance accorded to the rights, interests and inclusion of marginalized and vulnerable groups such as tribal populations, Dalits, and women (Katyaini et al. 2020; Van Wessel et al., 2019).

We conducted fieldwork in the two states of Bihar and Gujarat and in the capital Delhi. Both Bihar and Gujarat are prone to multiple hazards. Bihar is mostly affected by floods, earthquakes, and droughts. Because of sedimentcarrying perennial rivers originating in Nepal, 28 districts in the state are vulnerable to flooding in the monsoon months. Moreover, 32 districts of Bihar are vulnerable to earthquakes because of their proximity to the Himalayan tectonic plates in the Bihar-Nepal border area and the Gangetic plains. Gujarat is vulnerable to floods, earthquakes, droughts, cyclones, and other natural and manmade disasters. The 2001 earthquake in Bhuj, Gujarat, was a catalyst for establishing India's first State Disaster Management Authority (SDMA) in Gujarat and eventually resulted in the formation of the national-level NDMA. In both Bihar and Gujarat, the SDMAs have developed State Disaster management Plans (DMPs) through which disaster governance activities are implemented. For our study, these two states offered different governmental and CSO contexts, facilitating the analysis of patterns in the data between the states.

In each state, we interviewed staff members from two key state-level government agencies involved with disaster governance (Bihar: the Bihar SDMA and the Disaster Management Department; Gujarat: the Gujarat SDMA and the Gujarat Institute of Disaster Management). We also interviewed staff members from two key Delhi-based national-level authorities involved in disaster management (the NDMA and the National Institute of Disaster Management). The interviewees also included staff members from four Indian CSOs and three international NGOs working with government agencies on disaster management at the national, state, and/or district level; a consultancy agency; two intergovernmental agencies; and the secretariat of a national-level platform for governmental and non-governmental actors working on disaster governance. Finally, interviews were conducted with two former government employees who had been part of an SDMA and the NDMA and had worked extensively in disaster governance collaborations with different agencies and stakeholders. For confidentiality reasons, we have anonymized the names of the interviewees and CSOs. In total, we conducted 30 interviews with government officials and 12 interviews with CSO staff. Fieldwork was conducted August-December 2018. Using ATLAS.ti qualitative data analysis software, we analysed the data to identify patterns concerning the roles state agencies assign to CSOs, the criteria state agencies use to select CSOs to work with, the roles CSOs take up, and the ways CSOs navigate the roles offered by the state.

\section{India and State-Civil Society Relations}

Historically, relations between the Indian state and civil society have varied. The Nehruvian state of the first decades after independence in 1947 provided active political and financial support to CSOs, but civil society then suffered during Indira Gandhi's regime (1966-1977). The state experienced a growing crisis of governability and legitimacy, and several civil society movements emerged opposing Gandhi's rule, which led her to institute a state of emergency (1975-1977) and enact several laws restricting civil society's activities. However, soon after the 'Emergency', civil society was actively encouraged and supported by the Janata government (1977-1980). After assassination put an end to Indira Gandhi's final stint in power (1980-1984), the subsequent government of her son Rajiv Gandhi further promoted CSOs, making them active partners in inclusive development. However, since then, under neoliberalism, the Indian state has become increasingly intolerant towards civil society groups that oppose the government's market-driven development agenda. The Indian National Congress and the Bharatiya Janata Partyled governments of the past decades have taken different approaches to dealing with CSOs and marginalized communities. During their decade-long rule (2004-2014), the Indian National Congress tried to advance a form of 'inclusive neoliberalism'- 'market-oriented accumulation strategies coupled with social policy interventions that aim to protect poor and vulnerable groups from marginalization and dispossession' - which has been replaced by 'authoritarian populism' under the Modi government (Nilsen \& n.d., 2020 pp. 2-3). 
While both the Congress and BJP governments have imposed restrictions on civic space, the extent of these restrictions has increased, and tightening of laws controlling CSOs' access to foreign funding has been an important policy instrument. In some cases, it has selectively enforced these laws, appearing to restrict mainly the actions of groups taking a critical stance regarding human rights or environmental issues (Talukdar, 2018) and groups touching upon key economic interests. Stigmatization too has been made policy. These tendencies can be seen in the well-known instance of India's Intelligence Bureau accusing NGOs of 'reducing India's GDP by 2 to 3 per cent per annum, by campaigning against projects that the Indian government argued to be integral to economic growth' (Doane, 2016). CSOs have also been put under surveillance, and raids on CSO offices have been repeatedly reported in the media (see e.g. www.ndtv.com, 2018). Thousands of CSOs' licenses to receive foreign funding have been revoked for non-compliance (Chakrabarti 2018). A United Nations report classified Indian laws as unacceptable because of the risk that they will be used to silence CSOs whose views differed from those of the government (Kiai, 2016, p. 3). CSOs challenging the state are commonly delegitimized as 'anti-national' (Chacko, 2018). Academic freedom and freedom of the press have also been restricted (Chakrabarti et al., 2018). However, as different authors have noted, civic space does not shrink for all civil society actors affected to the same degree or in the same way (Hossain et al., 2018). While specific CSOs, journalists, activists and academics are countered by the state, thousands of CSOs continue to operate in India, including those with views and interests that are not in line with government agendas. Demonstrations continue to take place, although these have been met with violence on several occasions. And many CSOs are involved with the state in collaborations (Van Wessel et al., 2018). This begs the question how the differentiated relations are negotiated between the organizations involved. Disaster management is a domain where collaborative relations exist, while agendas and perspectives may differ, suggesting this domain as one suitable for the study of such negotiation.

\section{Disaster Governance in India and the Role of Civil Society}

The government's main disaster management policy documents profess an integrative approach in which prevention, preparedness, risk reduction, resilience, and recovery are central. As part of the United Nations International Decade for Natural Disaster Reduction in the 1990s, India established the National Centre for Disaster Management in 1995 (now the National Institute for Disaster Management) to plan and promote disaster management training and research and to develop disaster management policies, prevention mechanisms, and mitigation measures. Additionally, a high-powered committee was set up in 1999 to assess India's disasters and disaster vulnerability. In January 2001, an earthquake in the Kutch district of Gujarat provided the government with an opportunity to establish formal disaster management institutions. The State Disaster Management Authority (SDMA) for Gujarat was immediately established, followed by the National Disaster Management Authority (NDMA) in 2002. The Indian Ocean Tsunami in December 2004 called attention to the need for a national disaster management act articulating the roles and responsibilities of all governmental agencies in a disaster. The National Disaster Management Act was formally passed by Parliament in December 2005, followed by the more detailed National Policy on Disaster Management in 2009 (NDMA, 2009).

The National Policy on Disaster Management and the State Disaster Management Plans (DMPs) identify the roles, responsibilities, and expectations of all stakeholders, including government agencies, civil society, the corporate sector, and the media. These documents place the primary responsibility for disaster management on the state and its departments/agencies, but CSOs are regularly mentioned as stakeholders sharing this responsibility. While the CSOgovernment relationship is often defined as a partnership, most CSOs are involved in complementing roles (i.e. supporting capacity development, awareness raising, mobilization, relief, reconstruction, and rehabilitation) rather than representing groups or influencing policy development more broadly (Pal \& Shaw, 2018; Bahadur et al., 2016; NDMA, 2016; Gujarat SDMA, 2016-2017; Government of Bihar n.d.). Policy documents provide no insight into stateCSO collaborations as they have developed in reality. The limited research available reveals that CSOs have played roles in disaster management, including roles involving interaction with the government (e.g. Chatterjee et al., 2010; Vahanvati \& Mulligan, 2017). These roles are generally in line with the assigned roles mentioned above, but a few previous studies (e.g. Jones et al., 2016; Pal \& Shaw, 2018) and some policy documents (e.g. Government of Bihar, 2016) indicate that development organizations also conduct advocacy. However, the existing research offers limited insights into the strategizing involved, or the dynamics of the relations involved.

\section{Findings}

CSOs have been involved in disaster governance policy development and implementation in both Gujarat and Bihar, although different circumstances have shaped the two states' approaches to CSO collaboration. Our 
interviews in Gujarat revealed a fairly well-established bureaucratic machinery for disaster management, with a long chain of command down to the district level. In line with the State DMP, each district has its own District DMP and a District Project Officer responsible for overseeing all disaster-related operations, including (1) formulating a District DMP for multi-hazard risk and vulnerability assessment; (2) building an incident response system in case of disaster; (3) arranging equipment and resources; and (4) maintaining a list of community-based organizations in the district that can be contacted during an emergency. The District Project Officers mainly implement following SDMA directives, along with local government institutions; CSO involvement occurs only at the local level. There are some formal collaborations between CSOs and the Gujarat Institute of Disaster Management arranged through memoranda of understanding, with CSOs undertaking research and training activities for the Institute. In Bihar, district authorities hold the major responsibility for disaster management, and the SDMA works with CSOs to formulate and implement activities. Most CSOs working on disaster governance in Bihar have come together to form a recognized inter-agency group in which they exchange ideas and represent interests collectively to the government. The Bihar SDMA has also commissioned the formulation of District DMPs to nine CSOs.

At the state level in Bihar and at the national level, we found ad hoc and variable engagement with CSOs. In both states and in the national-level agencies, we found that these hinge on practical concerns. Participants from the state agencies acknowledged that CSOs were stakeholders in the disaster management process, and most believed that collaborations with CSOs were important. In their practical dealings with CSOs, they viewed CSOs' contribution very specifically in terms of providing required functional inputs. There appears to be an invisible hierarchy of organizations, where experience and resources are highly valued, with the state partnering with organizations with international and interstate experience and seeking their input for policy and programme planning. Local and statebased CSOs engaged in partnerships fulfil implementation roles, drawing on and building community ties. Below, we outline the different roles assigned to CSOs by state agency staff and then discuss the interviewees' criteria for selecting CSOs for collaboration.

\section{CSO roles}

\section{Problem-Solvers and Innovators}

The state agency interviewees had, to varying degrees, taken input from CSOs in the past, and they described CSOs as innovators and problem-solvers. They saw CSOs as offering technical knowledge and resolutions to locallevel issues, which the CSOs were thought to know well. The state agency interviewees viewed CSOs as trying to develop innovative solutions and to showcase best practices for the government to emulate. CSO-generated ideas were sometimes taken up or at least considered. A midmanagement staff member at the national-level authority on disaster management asserted that, 'For collaboration, the government looks for technical expertise, and to scale things up they need human resources and manpower. In the government sector, everyone has administrative or secretarial competencies. We need to outsource the work for technical expertise'. State agencies need assistance from national and international organizations, CSOs, and experienced individuals to advance disaster governance. In an interview, a senior manager of a state disaster management institute commented on such collaborations, saying, '[...] I need to have specialists, and all these people [CSOs] are experts and specialists in different areas. This is the only way to go ahead'. Technical service provision is thus where CSOs' research and analytical work come into disaster governance. On this topic, a researcher working on training and capacity building at the National Institute for Disaster Management in Delhi made the following comments:

We have called practitioners from various non-government organizations, lawyers, and medical practitioners and so on, who have done good work and have experience in the field, to be resource persons [...] We want to showcase best practices, and we call people who will be relevant for the programme we are conducting.

Likewise, an official from Gujarat stated, 'We have the Hazard Risk and Vulnerability Assessment prepared by a CSO for the whole state. We believe that the practicality should meet theory'. Another senior official said it was 'important to have the possibility of new innovations which can be scaled up. So, if the CSO is offering something new and sustainable, the government is willing to take it up if it sees merit'. In this way, owner-driven reconstruction has been taken up following disasters. Under this approach, after a disaster, homeowners source their own reconstruction materials with governmental funding, allowing them to design disaster-resistant houses in consultation with CSOs collaborating with the government in their region. Ownerdriven reconstruction hinges on state-CSO collaboration and values inclusiveness, with CSOs taking a leading role. Technical expertise and CSOs' values such as inclusive development can thus be integrated into policy development and implementation. However, state agencies consistently frame CSOs' 'technical' contributions in terms of their problem-solving nature rather than these values. Notably, state agencies do not necessarily make significant 
distinctions between different types of non-state actors, seeing knowledge institutes such as the Indian Institutes of Technology, intergovernmental agencies, and CSOs alike as sources of knowledge.

\section{Translators}

CSOs were also seen as translators. First, because CSOs worked at local levels, some were seen as well versed in local languages and able to deliver the state's message to the people more clearly than the state itself could. Second, CSOs were seen as intermediaries between the government and the people, providing two-way feedback. A state authority staff member noted that 'NGOs have a better rapport with the communities. They are able to communicate in the local language. In our department, most of us are not from this state [...]'. State agencies also relied on CSOs for translating books, manuals, and modules created by the national authority, customizing these materials by translating them into the local language and gearing them towards the local context.

\section{Implementing Agencies}

The state also considered CSOs to be implementing agencies. An SDMA staff member asserted that 'The ground-level implementation of all our programmes happens through civil society. We make the policy and plans, and they implement it for us'. Many CSOs have been called upon by government agencies to carry out awareness-raising programmes such as hospital safety and mock drills for hazards, especially in large companies and industrial areas. A district-level official from Gujarat said that 'Many agencies are given [the] responsibility to carry out these trainings and activities [...] because the government has no manpower. These agencies do the work on our behalf; we just approve which agency will carry out the work'.

\section{Extra Hands}

CSOs' work was also possible because the government saw them as resourceful 'extra hands'. These organizations were seen as having the necessary manpower and resources to provide last-mile connectivity, where the government often fell short. The CSOs' flexibility and experience in the field were thought to expedite the governance process. According to a mid-level management official from one of the SDMAs, 'It is important to work with CSOs and NGOs because the state cannot reach everywhere. These organizations have the people, resources, and reach through which they help the state'. A national-level mid-management official noted, 'We work with NGOs/CSOs in projects where we need technical support and human resources [...Programmes] cannot be run without [the] help of different agencies'. CSOs are thus seen as able to augment the state's efforts.

\section{Criteria for CSO Selection}

In the interviews with state agency and CSO staff members, we found that state agencies use relational, organizational, and performance criteria in CSO selection.

\section{Relational Criteria}

We identified three specific relational criteria, which concern CSO-government relations: trustworthiness of the CSO, working in complementarity with the state while being non-threatening, and contributing non-governmental financial resources. First, in the state's view, the CSOs with which they collaborate should be trustworthy. This appeared to mean that collaboration should not have undesirable implications for the government. An international NGO representative provided an example of this:

If we ask for information that the government considers sensitive, they know that we will not release it to the media or misuse the information. For example, if during floods we ask which are the most affected districts or blocks so that we can extend our services there, they may tell us, but they may not be in a position to release this information to the media. It might become a political issue $[. .$.

CSOs are also expected to complement the state's work by helping to fill gaps, while avoiding being threatening to the state, meaning not contesting the government's claims and having no history of radical thought or anti-state protest. Some interviewed CSO staff members asserted that the state does not want open opposition to its work and that CSOs able to understand and comply with this can win the state's trust. The CSOs were sensitive to this issue, and many altered their approach to make themselves more relevant and visible to the state, moving away from confrontation and towards more collaborative relations with the state. A representative of an international NGO in Bihar summarized this as follows:

Earlier, NGOs were of an activist type; zaraa sa kuch hua to jhanda-danda lekar nikal jaate the [with a little bit of provocation, we all used to take out flags and be ready for a protest]. But now the approach has changed. We do not compete with the government. We supplement their work.

A third dimension of relational criteria involves the capacity of some CSOs to work with non-governmental 
resources, which, in addition to being financially helpful to the government, also helps disaster governance to proceed in a more timely and flexible way. All governmental funding, regardless of urgency, must go through a tendering process. A former SDMA civil servant explained this as follows:

For work in the government, funding provisions are outlined [...] Funding or money is important to sort out beforehand because, for the government, money means accountability and transparency in its spending. Since they are dealing with public funds, everyone has a right to know where it is being spent.

CSOs working with non-governmental funding and/or with access to local resources such as fishing boats (for rescue operations) can bypass the arduous and time-consuming tendering process. Describing this situation, a senior national-level official said, 'They [CSOs] should have the adaptability to dovetail the capacity of the government and the local resources because the government will always go by a standard procurement procedure to get any material required'. Formal work with the government operates through memoranda of understanding and expressions of interest, where both parties list specific objectives and outline the funding modalities, but some organizations prefer to work without governmental funding. However, most interviewed CSO representatives did not express this preference. Whereas international NGOs, intergovernmental agencies, and other large NGOs and CSOs, as specialized institutions with multiple intellectual and material resources, might be able to work without government funding, local NGOs and smaller district- or community-based organizations are not in a position to do this.

\section{Organizational Criteria}

The second set of criteria concerns CSOs' reputations. Government agencies require CSOs to be effective and efficient, and to have non-criminal and 'non-partisan' ways of working. A representative of an international NGO in Delhi articulated this as follows:

The reasons that the government works with any CSO is, to put it in a nutshell, what values you bring to the table. It is not only about what work you do, but also how you deliver the things you have promised. The government is aware of all organizations, but the ability of an organization to encapsulate the learnings and provide the deliverables is important.

Many interviewees discussed CSOs' reputations in a similar way, and reputation was repeatedly described as a distinguishing feature for CSOs. A senior representative of a Gujarat-based CSO described the importance of reputation as follows:

While working [for one of the projects], we got to know that the state agency referred to us as khul ja sim-sim ${ }^{1}[\ldots]$ They used to tell us that 'Everyone tells us the problems we already know about, and we want solutions. You offer that to us'.

Moreover, in light of the Indian government's crackdown on NGOs and CSOs, as well as the exposure of criminal offences taking place in a CSO-managed orphanage in Bihar in 2018, organizations were cautious in their dealings with government agencies and with other CSOs. They expressed an awareness that the government would not partner with them if their reputation became tarnished, which could happen because of non-compliance with norms or even interaction with other organizations labelled as troublemakers by the government.

\section{Performance Criteria}

The final set of criteria concerns CSOs' performance. Each CSO has its own expertise and themes. These eventually become its specializations-areas where the CSO has proven its quality - and several interviewees explained that being seen as having expertise in particular specializations was a main reason why government agencies sought collaboration with them. An intergovernmental agency representative said, 'The basis of the relationship depends on the faith that the government has in the organization's work, in the quality of work already showcased, and that they have proven themselves in the area'. Relatedly, other interviewees pointed out the importance of having done 'good work' in the field, which leads to a good organizational reputation for a particular specialization. Having done 'good work' was also seen to aid in gaining social acceptance in communities where the organization worked; this could, in turn, be important to government agencies, as discussed above.

Figure 1 elaborates the various roles envisioned for CSOs by the state and the qualities the state looks for in selecting CSOs for collaboration. These roles and criteria provide a sense of the interplay between the state agencies and the CSOs, from the state's perspective. It is possible that the interviewees left out certain reasons for collaboration and overemphasized others, purposely framing their considerations in publicly acceptable discourse and including certain aspects for legitimation purposes rather than seeking to reflect their actual rationales. For example,

\footnotetext{
$\overline{1}$ A colloquial phrase equivalent to 'open sesame', the magical phrase used to open a cave of treasures in the folktale of Ali Baba and the forty thieves.
} 
Fig. 1 State agency interviewees' assignment of roles for CSOs, and their considerations
Roles

Considerations

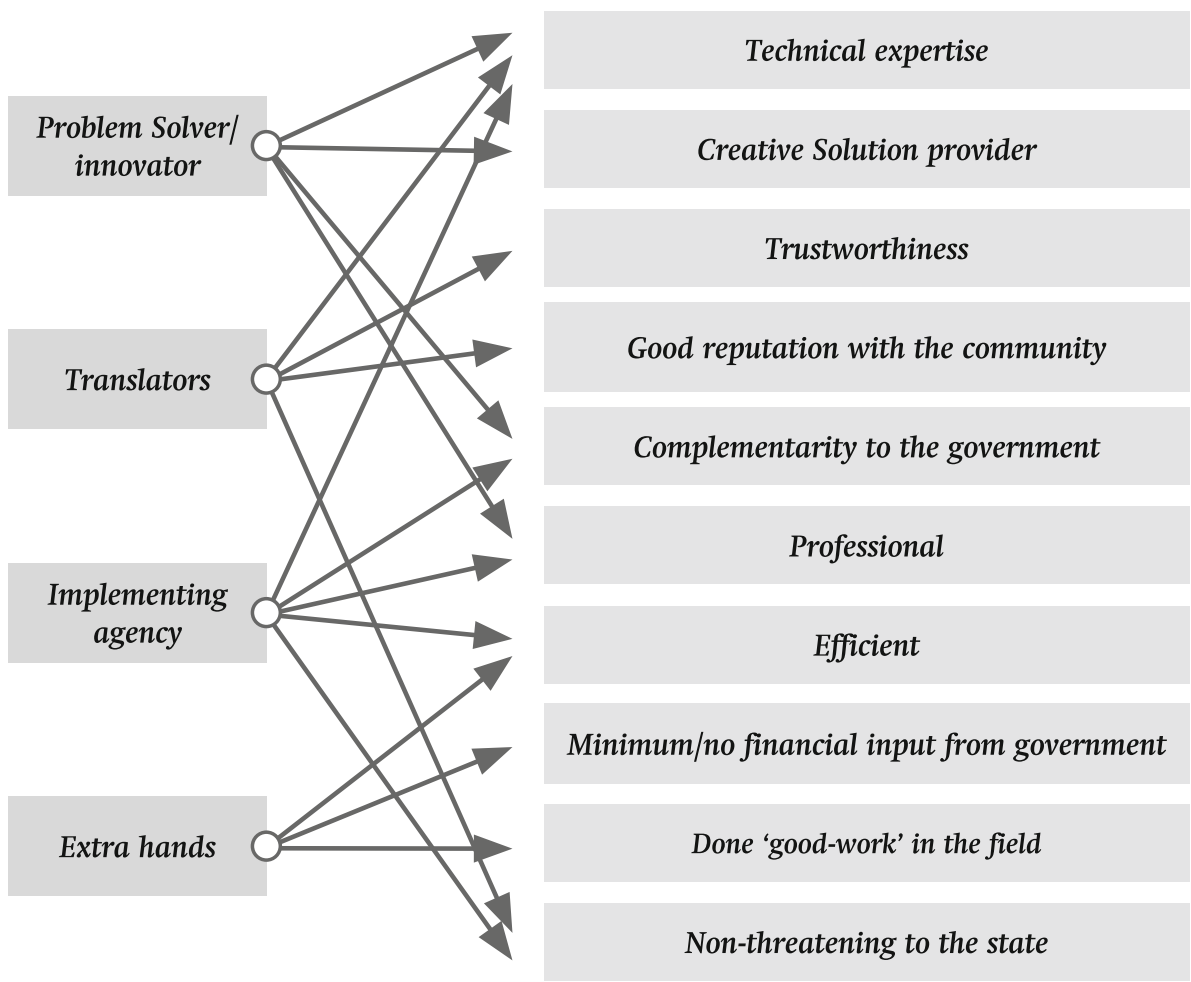

we could not expect corruption-based criteria, which may be common (Asian Centre of Human Rights, 2013), to be shared easily and openly in our research interviews. However, the nature of the shared discourse is nevertheless telling, revealing at least the forms of reasoning interviewees appeared to see as publicly legitimate. It is similarly telling that scant space was given to CSOs' representative roles. Their roles as actors giving voice to society, contesting the state, and holding it accountable received little mention or were rejected. Instead, the delivery of politically unproblematic 'results' was described as important. The above discussions also bring to light CSOs' awareness of the roles and criteria considered most important for the state, as well as CSOs' sensitivity to these and their general will to mould themselves accordingly. The next section elaborates on the nature of state-CSO collaborations as understood by the interviewed CSO staff and describes how CSOs manoeuvred within the space offered by the state.

\section{CSOs' Collaborations with the State}

Representatives of CSOs working with the state agreed that the space for civil society had been shrinking and was quite constricted at the time of the data collection. These organizations try to work within the space provided. Through collaborations, they develop different relations with the state, often through personal relationships with officials who are open to this and at least partially like-minded, and CSOs negotiate their roles within these collaborations. On the basis of our interviews with CSO staff, we constructed three ways in which CSOs working on disaster governance in India collaborate with the state. The distinctions between these approaches are not definite, and roles taken up by CSOs may overlap. Moreover, despite important differences between them, the three approaches to collaboration show significant similarities in how roles are defined by the state, with limited space for deviation from state agendas. At least some CSOs seek to work with these agendas to insert their own priorities to the extent possible, given existing constraints.

Working with the state. The first approach to collaboration is working with the state. Most CSOs working in partnership with the state reported constant communication with the state, providing technical input, giving feedback from the field, and participating in discussions to develop and improve policy. These CSOs thus have a constructive interface with the government, characterized by mutual learning. Here, CSOs' thematic and technical expertise comes into play most vividly. To push the government to bring about change in the governance process, CSOs share their experiences of negotiations and of steering/manoeuvring within the limited space available. In some cases, CSOs are brought into policy development processes to 
provide policy advice. In other cases, interviewees argued that the idea is not to change existing policy, but rather to change its implementation to make the policy more meaningful. In this work, CSOs attempt to appear more relevant and interesting to the state, without directly challenging the government. From this perspective, field examples were seen as the best way for CSOs to convey their points. CSOs' experience in the field lends a sense of genuineness to their cases, and they use examples and best practices to support their arguments. This also demonstrates CSOs' impact in the field and helps to build state institutions' faith in the CSOs' capacity and the genuineness of their work. CSOs and the government may also share agendas, and CSOs can be brought in to help with inclusiveness, as seen in owner-driven reconstruction, as discussed above. Some interviewed CSO representatives stressed that their work involves advocacy, as they seek to advance their own (rights-based) agendas where they found the government's agenda wanting, with CSOs aiming, for example, for more inclusive housing reconstruction policies or better access to education during emergencies. Some CSOs thus did not feel that collaboration led them to relinquish their agendas. As one interviewee stated, 'We have never been an advocacy and activist kind of organization. But we have not given up on our rights-based approach'. Some CSOs pursuing rights-based agendas reported a certain amount of success, with the government taking up their ideas in some form. For example, the staff of a CSO working on gender-based violence, after learning that adolescent girls face an increased risk of trafficking during disasters, presented an evidence-based case for training on this topic for government officials, and this proposal was taken up. However, representatives from other CSOs were disappointed regarding their influence, expressing exasperation that governmental agencies 'take what they need' and ignore other input, thus treating the CSOs as vendors.

\section{Working as the State}

The second approach to collaboration, working as the state, involves policy implementation roles, where CSOs are authorized by the state to carry out particular activities on its behalf. Activities included in this type of collaboration are, for example, ground-level implementation of government policies, coordination activities, and the execution of various training programmes and mock drills. Here, CSOs are engaged mostly because of their innovative ideas and problem-solving capabilities. However, CSOs' roles go beyond those of implementing agencies. To some extent, CSOs tweak their roles in response to the state's expectations, acknowledging that questioning the government-as long as this is not done on public platforms-allows suggestions and solutions to flow more freely. This approach allows CSOs to contribute their own expertise and innovative solutions and to negotiate with the state to open up space to pursue their agendas. An interviewee from a CSO in Gujarat said, 'We push our agenda in a gentler manner [...] We ask difficult questions to government agencies. They are forced to think about the issues. There is a difference between contractual work and partnership'. CSOs thus engage the state in situations where the state is seen to fall short, questioning the state regarding its intent, implementation mechanisms, and capacity. It may also be possible to insert CSOs' agendas through the underthe-radar tweaking of activities. For example, representatives from one CSO explained that, when working on a project, they select districts in such a way to ensure the inclusion of certain disadvantaged populations, without confronting the government about inclusion. However, CSOs realize that that the state is itself stretched and cannot perform all necessary tasks, and their questioning is not intended to threaten the state.

\section{Working for the State}

CSOs' role as translators connecting the state and communities emerges most clearly in working for the state, the third approach to collaboration. The state may commission work, such as creating a hazard risk vulnerability report, drawing up a District DMP, or customising national-level guidelines, with minimum state involvement. For example, CSOs may be asked to develop a District DMP because they know the local context and disaster risks, enabling them to tailor the DMP appropriately. Locally active CSOs have a key role to play here because they are seen and engaged and having a good local understanding and reach. Their local knowledge allows them to act as local-level translators, carrying out work assigned by the state and helping the state with last-mile connectivity. Their rapport with local populations, local knowledge, and language capacities facilitate making state plans meaningful for local conditions and communicating these plans to local people, while also inserting local needs into the process. CSOs' own perspectives may also be relevant here. An interviewee whose CSO had been involved in drafting District DMPs asserted, 'We do not implement the government's plan exactly. We try to give our own inputs for the District Disaster Management Plan'.

\section{Space for CSOs as Representatives}

Within the above approaches to collaboration, there appears to be some space for CSOs to bring in their own agendas. However, the state's agenda is leading in each role. In addition, the interviewees regularly expressed the 
importance of being on guard to avoid confrontation in developing and maintaining collaborations with the state. CSOs monitor the space available within the roles offered to them in collaborations and interpret the possibilities. The interviewees spoke of decreased trust between CSOs and the state, limited recognition of CSOs, a turning away from collaboration with CSOs in recent years, and the will of the state to control CSOs. To enable collaboration, the studied CSOs had at least partially adjusted to these new conditions. One CSO interviewee noted that they 'don't ask too many questions, but deliver the work'. The leading role of the state was also accepted: CSO representatives expressed that 'We are not competitors to the government' and 'We are here to complement the government, not to replace it or antagonize it'. Some CSO staff explained that their success in attaining trust, seen as the foundation for collaboration, was based on their performance: 'Our work becomes the basis for trust-building'; 'We have delivered on our promises'; 'The government looks for us because we are experts in the area'; and 'The basis of the relationship is the faith that the government has in the organization or the work already showcased'. CSOs thus tread carefully, understanding that any collaboration depends on their capacity to deliver on set expectations framed in instrumental terms. CSOs' representative role of giving voice to causes, interests, and viewpoints in society has not been entirely abandoned, but, at least among the CSO interviewees in the present study, fulfilling this role is contingent on creating possibilities within collaborations, accepting limits set by the state. We should note here, however, that outside of the 'invited' spaces of collaboration, representative roles may also develop, and likely more freely, in 'claimed', self-organized spaces outside of the realm of direct collaboration with the state, as recently shown by Katyaini et al., (2021).

\section{Discussion and Conclusion}

The shaping of CSOs' roles through collaboration under conditions of restricted civic space is only partly defined by the across-the-board restrictive policies that have been the focus of much existing research on restricted civic space and its implications for CSOs. The interplay between specific state actors and CSOs turns out to be important for the shaping of CSOs' roles. This is where this paper's contribution to the debate on CSOs' roles in constricted civic space lies: in showing how interplay at the level of individual state agencies and CSOs, based on mutual perceptions, diverse organization-level considerations and actions, and evolving relations, shape who collaborates with whom and to what effect. Shedding a rare light on these relations at micro-level, our findings provide three main insights into the nature of the interplay involved. First, this interplay defines who has a chance to be in and for what purposes, through multiple selection criteria and the roles state actors offer to CSOs, and the sensitivity of CSOs towards these criteria and role offerings. Secondly, within collaborative relations, CSOs seek to comply but may also use the relations of trust that develop to insert elements of their own agendas. While pressure from the state limits space for representation that is critical of the state, collaborations may open space for the careful insertion of CSOs' agendas as interdependencies and trust develop, for the addition of expertise that advances the values of inclusive development, and for the under-theradar inclusion of multiple perspectives in policy implementation and in other areas. Co-optation seems to happen, but without CSOs necessarily relinquishing their agency and strategic acumen. The careful management of relations and forms of communication appears to be of key importance here. Third, the different roles of working, with, as and for the state may each provide different possibilities of inserting CSO agendas. Clear distinctions between 'types' of CSOs as oriented towards either service delivery or advocacy, loyal or independent, as seen in some existing literature (e.g. Toepler et al., 2020) thereby turn out to be too crude as reality can be both more fine-grained and dynamic. While small-scale and limited to a single policy domain and context, our article hereby offers a novel angle towards researching the possibilities of CSO roles under conditions of restricted civic space; with more attention to the importance of interplay.

However, the findings also indicate the limits of the possibilities, and insights into this form a second way in which this paper contributes to the debate on civic space: the interplay only goes so far as the state allows, and the CSOs interviewed for this study appear to stay within the conditions the state imposes. State agencies in the domain of disaster governance work with CSOs when they think this is useful, asking of CSOs to show specific qualities and behaviour that are in line with these understandings of usefulness, while rejecting other qualities and behaviour often thought to be important to CSO roles, such as holding government to account. Based on these criteria, state actors offer limited roles for civil society, and CSOs in this context are sensitive to the criteria and role expectations. CSOs assess the space offered by the state and manoeuvre their interventions to maximize the benefit to all stakeholders, including the state, communities, people they seek to work for and represent, and themselves. The state and CSOs may be aligned in their ambition to address certain inequalities, vulnerabilities, and exclusions. But CSOs also often self-censor to avoid sensitivities such as appearing too critical, publicly contesting state claims, or associating with other CSOs with confrontational stances or possibly 
even a less favourable image. Moreover, collaborations such as those discussed in this study may also contribute to silencing CSOs as they seek to protect their relations with the state.

With this, our findings lead us to suggest a deeper and disturbing significance of the limits we see for the possibilities of CSO roles within collaboration as we see in this case study. Research on civil society in authoritarian and hybrid regimes has stressed detrimental consequences for civil society's role of producing and sharing perspectives alternative to dominant state perspectives (Lewis, 2013, p. 337). Within the collaborations we studied, CSOs steer clear from such producing and sharing of perspectives. Certainly, CSOs propose ways for disaster governance to be more inclusive and insert related agendas into policy development and implementation. However, this likely cannot go much beyond understandings of inclusive development that have already been accepted by the state (cf. Mitlin et al., 2007), or at least the CSOs appear to accept this limit. Moreover, the acceptance of a focus on 'performance' in terms of delivery in collaborations shows CSOs largely falling in line with the regime. In addition, relatively politically oriented CSOs working on disaster governance appear to find themselves largely excluded from the state-CSO collaborations discussed in this article (Katyaini et al., 2021; Van Wessel et al., 2019). This is particularly important considering that disasters (like many other issues on which states and CSOs collaborate) are potentially highly political in multiple ways, including the definition of disaster, the political capital disasters may bring to actors such as states, and different ideas about risks and responsibilities (Warner, 2013). Addressing disasters' root causes can also be very political, challenging economic and political power relations at multiple levels. However, no CSOs involved in the present study sought to politicize disaster, indicating important limits to their role as voices of society and sources of alternatives, within collaborations with the state.

With many states around the world tightening control over civil society, the question of how to relate to such conditions when it comes to collaborating with the state is highly pertinent for CSOs, academics, and donors. This study points to CSO agency, and the requirement of skilful manoeuvring within specific relations. It thereby raises for CSOs questions of what they can or should do in contexts of restricted civic space, considering dilemmas they may face between following ideals of autonomy and voice, leading to exclusion and persecution, and the potential of continued relevance (within limits). As one CSO interviewee commented, 'Working with the government can be a source of life or a kiss of death': Working with state agencies can create possibilities to do good work, but, if someone angers a state official, it can lead to their CSO being blacklisted. CSOs thus often try to tread carefully, seeking to manage their work under both more and less favourable conditions. What could be appropriate policies for CSOs for handling constraints and approaching possibilities, seeking to maintain or develop some space for their own agendas or to critique the state? Denouncing CSOs' efforts to work within limits as simple co-optation may fail to do justice to CSOs' actual engagement with their work and efforts to overcome the dilemmas they face. Future research may seek to do more justice to this than we could do in this small-scale, domain-specific study. Academics studying the role of CSOs can approach them as agents struggling with civic space issues and looking for ways to find a meaningful role in a specific policy domain, aware of the limits in place and their constraining effects. Academics can also undertake studies of the nature of CSOs' agency in specific roles (e.g. working with, as or for the state) in collaborations with government agencies under conditions of constricted civic space. In that regard, this exploratory study has offered a novel angle, but it has only scratched the surface.

When it comes to donors, we suggest for them to consider CSOs as agents navigating their possibilities within specific political and policy contexts, supporting their efforts to contribute to inclusive development under challenging circumstance, facing dilemmas but also options that they may build and capitalize on. However, we also find it wise for donors to consider the limits this agency may run into, and the conditions under which to support CSOs working with government agencies in contexts of restricted civic space.

Acknowledgements We thank the staff of state agencies and CSOs we interviewed for sharing their thoughts and experiences with us. We also thank Jennifer B. Barrett for editorial support.

Funding This study was funded by NWO-WOTRO grant number W 08.311.104.

\section{Declarations}

Conflict of Interest The authors declare that they have no conflict of interest.

Open Access This article is licensed under a Creative Commons Attribution 4.0 International License, which permits use, sharing, adaptation, distribution and reproduction in any medium or format, as long as you give appropriate credit to the original author(s) and the source, provide a link to the Creative Commons licence, and indicate if changes were made. The images or other third party material in this article are included in the article's Creative Commons licence, unless indicated otherwise in a credit line to the material. If material is not included in the article's Creative Commons licence and your intended use is not permitted by statutory regulation or exceeds the permitted use, you will need to obtain permission directly from the copyright holder. To view a copy of this licence, visit http://creativecommons. org/licenses/by/4.0/. 


\section{References}

Amarasingam, A., \& Argentino, M. A. (2020). The QAnon conspiracy theory: A security threat in the making. CTC Sentinel, 13(7), $37-44$.

Asian Centre of Human Rights. (2013). India's funds to NGOs squandered. http://www.achrweb.org/info-by-country/india/ indias-funds-to-ngos-squandered/. Retrieved April 29, 2020.

Bahadur A., Lovell E., \& Pichon F. (2016). Strengthening disaster risk management in India: A review of five state disaster management plans. http://www.indiaenvironmentportal.org.in/ files/file/Strengthening\%20disaster\%20risk\%20management $\%$ 20in\%20India.pdf. Retrieved October 1, 2019.

Bebbington, A. J., Hickey, S., \& Mitlin, D. C. (2008). Introduction: Can NGOs make a difference? In A. J. Bebbington, S. Hickey, \& D. C. Mitlin (Eds.), Can NGOs make a difference? The challenge of development alternatives (pp. 3-37). Zed Books Ltd.

Broeckhoven, N., Reda, K. T., Townsend, D., \& Verschuuren, J. (2020). CSOs in sustainable development in ethiopia: Past practices and new trajectories. African Journal of Legal Studies, 1(aop), 1-30.

Buyse, A. (2018). Squeezing civic space: Restrictions on civil society organizations and the linkages with human rights. International Journal of Human Rights, 22(8), 72-91.

Carothers, T., \& Brechenmacher, S. (2014). Closing space: democracy and human rights support under fire. Carnegie Endowment for International Peace.

Chacko, P. (2018). The right turn in India: Authoritarianism, populism and neoliberalisation. Journal of Contemporary Asia, 48(4), 541-565.

Chakrabarti, K., Saravanamuttu, P., Tahseen, M., Wu, C.E., Magno, F.A., \& Thu, M., (2018). Civic space in Asia: Emerging issues and policy lessons from six Asian countries. http://www.eai.or. $\mathrm{kr} / \mathrm{main} /$ english/search_view.asp?intSeq=9581\&board=eng_report. Retrieved May 1, 2019.

Chambers, S., \& Kopstein, J. (2001). Bad civil society. Political Theory, 29(6), 837-865.

Chandhoke, N. (2001). The 'civil' and the 'political' in civil society. Democratization, 8(2), 1-24.

Chatterjee, A., Gupta, D., \& Jain, N. (2010). Coordination of disaster response: potential and challenges from Indian experiences. https://pdfs.semanticscholar.org/6513/2776acce77071355ad30e2 b08498504881a1.pdf . Retrieved September 18, 2019.

CIVICUS (2020) The state of civil society Report. https:// www. CIVICUS.org/index.php/state-of-civil-society-report-2020. Retrieved August 15, 2020.

Doane, D. (2016). The Indian government has shut the door on NGOs. The Guardian, September 7. https://www.theguardian.com/globaldevelopment-professionals-network/2016/sep/07/the-indian-gov ernment-has-shut-the-door-on-ngos. Retrieved January 13, 2020.

Dupuy, K., Ron, J., \& Prakash, A. (2016). Hands off my regime! Governments' restrictions on foreign aid to non-governmental organizations in poor and middle-income countries. World Development, 84, 299-311.

Fransen, L., Dupuy, K., Hinfelaar, M. Mazumder,S.M.Z. Sharp, W. (2020). Adjust, resist or disband? The effect of political repression on civil society organizations in Bangladesh and Zambia. https://includeplatform.net/wp-content/uploads/2020/ 01/Fransen_Rearch_report.pdf. Retrieved September 13, 2020.

Giersdorf, S., \& Croissant, A. (2011). Civil society and competitive authoritarianism in Malaysia. Journal of Civil Society, 7(1), $1-21$.

Government of Bihar. (2016). Roadmap for disaster risk reduction 2015-2030, revised draft. http://www.disastermgmt.bih.nic.in/
Circulars/Draft_Bihar_DRR\%20Roadmap.pdf. Retrieved October $5,2019$.

Government of Bihar, Disaster Management Department, (n.d.). The State Disaster Management Plan. http://disastermgmt.bih.nic.in/ bsdma\%20plan/00\%20INDEX.pdf. Retrieved October 5, 2019.

Gujarat State Disaster Management Authority. (2016-2017). Gujarat State Disaster Management Plan. Volume 1. http://www.gsdma. org/uploads/Assets/other/gsdmp-2016-17-volume-10607201711 5412038.pdf. Retrieved October 5, 2019.

Heiss, A. (2017). Amicable contempt: The strategic balance between dictators and international NGOs. Doctoral dissertation, Duke University.

Hossain, N., Khurana, N., Mohmand, S., Nazneen, S., Oosterom, M., Roberts, T., Santos, R., Shankland, A., \& Schröder, P. (2018). What Does Closing Civic Space Mean for Development? A Literature Review and Proposed Conceptual Framework. Sussex: Institute of Development Studies.

Jones, S., Oven, K. J., \& Wisner, B. (2016). A comparison of the governance landscape of earthquake risk reduction in Nepal and the Indian State of Bihar. International Journal of Disaster Risk Reduction, 15, 29-42.

Katyaini, S., \& Wessel, M., \& Sahoo, S. (2021). Representation by development organizations. Evidence from India and implications for inclusive development. Journal of Environment \& Development 30(1): 98-123.

Kiai, M. (2016). Analysis of International Law, Standards and Principles Applicable to the FCRA Act 2010 and Rules 2011. Geneva: Office of the United Nations High Commissioner for Human Rights. https://www.ohchr.org/Documents/Issues/FAsso ciation/InfoNoteIndia.pdf. Retrieved March 24, 2021.

Krygier, M. (1996). The Sources of Civil Society. Second Richard Krygier Memorial Lecture. https://www.abc.net.au/radiona tional/programs/backgroundbriefing/the-sources-of-civil-society/ 3563756. Retrieved December 2, 2020.

Kulmala, M. (2016). Post-Soviet "political"?: "Social" and" political" in the work of Russian socially oriented CSOs. Demokratizatsiya: The Journal of Post-Soviet Democratization 24(2): 199-224.

Lewis, D. (2013). Civil society and the authoritarian state: Cooperation, contestation and discourse. Journal of Civil Society, 9(3), 325-340.

Lorch, J., \& Bunk, B. (2017). Using civil society as an authoritarian legitimation strategy: Algeria and Mozambique in comparative perspective. Democratization, 24(6), 987-1005.

Ministry of Law and Justice. (2005). National Disaster Management Act. https://ndma.gov.in/images/ndma-pdf/DM_act2005.pdf. Retrieved May 11, 2019.

Mitlin, D., Hickey, S., \& Bebbington, A. (2007). Reclaiming development? NGOs and the challenge of alternatives. World development, 35(10), 1699-1720.

National Disaster Management Authority. (2009). National Policy on Disaster Management. Available at: https://ndma.gov.in/images/ guidelines/national-dm-policy2009.pdf. Retrieved October 10, 2019.

Nilsen, A.G. (n.d.). From Inclusive Neoliberalism to Authoritarian Populism: Trajectories of Change in the World's Largest Democracy. https://www.academia.edu/36270820/From_Inclu sive_Neoliberalism_to_Authoritarian_Populism_Trajectories_of_ Change_in_the_Worlds_Largest_Democracy. Retrieved January 13,2020 .

O'Donnell, G., \& Schmitter, P. (1986). Transitions from Authoritarian Rule. Johns Hopkins University Press.

Pauly, R., De Rynck, F., \& Verschuere, B. (2016). The Relationship Between Government and Civil Society: A Neo-Gramscian Framework for Analysis. https://biblio.ugent.be/publication/ 8065871/file/8065904.pdf. Retrieved March 24, 2021. 
Pal, I., \& Shaw, R. (Eds.). (2018). Disaster Risk Governance in India and Cross Cutting Issues. Springer.

Rutzen, D. (2015). Authoritarianism goes global (II): Civil society under assault. Journal of Democracy, 26(4), 28-39.

Sahoo, S. (2013). Civil Society and Democratization in India. Routledge.

Skokova, Y., Pape, U., \& Krasnopolskaya, I. (2018). The non-profit sector in today's Russia: Between confrontation and co-optation. Europe-Asia Studies, 70(4), 531-563.

Spires, A. J. (2011). Contingent symbiosis and civil society in an authoritarian state: Understanding the survival of China's grassroots NGOs. American Journal of Sociology, 117(1), 1-45.

Tadesse, H.A., \& Steen, T. (2019). Exploring the impact of political context on state-civil society relations: Actors strategies in a developmental state. VOLUNTAS: International Journal of Voluntary and Nonprofit Organizations 30: 1256-1269.

Talukdar, R. (2018). Sparking a debate on coal: Case study on the Indian Government's crackdown on Greenpeace. Cosmopolitan Civil Societies: an Interdisciplinary Journal, 10(1), 45-62.

Toepler, S., Zimmer, A., Fröhlich, C., \& Obuch, K. (2020). The changing space for NGOs: Civil society in authoritarian and hybrid regimes. VOLUNTAS: International Journal of Voluntary and Nonprofit Organizations, 31(4): 649-662.

Vahanvati, M., \& Mulligan, M. (2017). A new model for effective post-disaster housing reconstruction: Lessons from Gujarat and Bihar in India. International Journal of Project Management, 35(5), 802-817.

Van der Borgh, C., \& Terwindt, C. (2012). Shrinking operational space of NGOs-A framework of analysis. Development in Practice, 22(8), 1065-1081.

Van der Borgh, C., \& Terwindt, C. (2014). NGOs Under Pressure in Partial Democracies. Palgrave Macmillan.
Van Wessel, M., Katyaini, S., Mishra, Y., Naz, F., Balasubramanian, R., Manchanda, R. \& Sahoo, S. (2019). Civil Society Dynamics: Shaping Roles, Navigating Contexts. Wageningen: Wageningen University \& Research. https://library.wur.nl/WebQuery/wur pubs/fulltext/511476. Retrieved September 13, 2020.

Van Wessel, M., Naz, F., \& Sahoo, S. (2020). Complementarities in CSO Collaborations: How working with diversity produces advantages. VOLUNTAS: International Journal of Voluntary and Nonprofit Organizations, 1-14.

Van Wessel, M. G. J., Rajeswari, S., Naz, F., Mishra, Y., Katyaini, S., Sahoo, S., \& Deo, N. (2018). Navigating Possibilities of Collaboration: How Representative Roles of Diverse CSOs Take Shape: a Literature Review. Wageningen: Wageningen University \& Research. https://library.wur.nl/WebQuery/wur pubs/fulltext/504984. Retrieved February 12, 2021

Warner, J. (2013). The politics of 'catastrophization.' In D. Hihorst (Ed.), Disaster, Conflict and Society in Crises: Everyday Politics of Crisis Response (pp. 92-110). Routledge.

Weinstein, J. M., \& Christensen, D. (2013). Defunding dissent: Restrictions on aid to NGOs. Journal of Democracy, 24(2), 77-91.

Wischermann, J., Bunk, B., Köllner, P., \& Lorch, J. (2018). Do associations support authoritarian rule? Evidence from Algeria, Mozambique, and Vietnam. Journal of Civil Society, 14(2), 95-115.

www.ndtv.com. (2018). Amnesty International Bengaluru office raided by Enforcement Directorate. https://www.ndtv.com/indianews/amnesty-international-office-in-bengaluru-raided-by-enfor cement-directorate-1937660. Retrieved September 5, 2019.

Publisher's Note Springer Nature remains neutral with regard to jurisdictional claims in published maps and institutional affiliations. 